\title{
Left ventricular filling characteristics in pulmonary hypertension: a new mode of ventricular interaction
}

\author{
B B Stojnic, S J D Brecker, H B Xiao, S M Helmy, M Mbaissouroum, D G Gibson
}

\begin{abstract}
Objective-To examine the effects of pulmonary hypertension on left ventricular diastolic function and to relate the findings to possible mechanisms of interdependence between the right and left sides of the heart in ventricular disease.
\end{abstract}

Design-A retrospective and prospective analysis of echocardiographic and Doppler studies.

Setting-A tertiary referral centre for both cardiac and pulmonary disease.

Patients-29 patients with pulmonary hypertension (12 primary pulmonary hypertension, 10 pulmonary fibrosis, five atrial septal defect (ASD), and two scleroderma) were compared with a control group of 10 patients with an enlarged right ventricle but normal pulmonary artery pressure (six ASD, one after ASD closure, one ASD and pulmonary valvotomy, one tricuspid valve endocarditis and repair, and one pulmonary fibrosis). None had clinical or echocardiographic evidence of intrinsic left ventricular disease.

Main Outcome measures- $M$ mode echocardiographic measurements were made of septal thickness, and left and right ventricular internal cavity dimensions. Doppler derived right ventricular to right atrial pressure drop, and time intervals were measured, as were isovolumic relaxation time, and Doppler left ventricular filling characteristics.

Results-The peak right ventricular to right atrial pressure gradient was (mean (SD)) 60 (16) $\mathrm{mm} \mathrm{Hg}$ in pulmonary hypertensive patients, and 18 (5) $\mathrm{mm} \mathrm{Hg}$ in controls. The time intervals $P_{2}$ to the end of the tricuspid regurgitation, and $P_{2}$ to the start of tricuspid flow were both prolonged in patients with pulmonary hypertension compared with controls (115 (60) and $120(40) v 40(15)$ and 45 (10) ms, p values $<0.001)$. Pulmonary hypertensive patients commonly had a dominant $A$ wave on the transmitral Doppler (23/29); however, all the controls had a dominant $\mathbf{E}$ wave. Isovolumic relaxation time of the left ventricle was prolonged in pulmonary hypertensive patients compared with controls, measured as both $A_{2}$ to mitral valve opening ( 80 (25) $v$
50 (15) $\mathrm{ms}$ ) and as $A_{2}$ to the start of mitral flow (105 (30) $v 60$ (15) ms, p values $<0.001)$. The delay from mitral valve opening to the start of transmitral flow was longer in patients with pulmonary hypertension (30 (15) ms) compared with controls (10 (10) ms, p $<0.001)$. At the time of mitral opening there was a right ventricular to right atrial gradient of 12 (10) $\mathrm{mm} \mathrm{Hg}$ in pulmonary hypertensive patients, but this was negligible in controls $(0.4(0.3) \mathrm{mm} \mathrm{Hg}, \mathrm{p}<0.001)$.

Conclusions-Prolonged decline of right ventricular tension, the direct result of severe pulmonary hypertension, may appear as prolonged tricuspid regurgitation. It persists until after mitral valve opening on the left side of the heart, where events during isovolumic relaxation are disorganised, and subsequent filling is impaired. These effects are likely to be mediated through the interventricular septum, and this right-left ventricular asynchrony may represent a hitherto unrecognised mode of ventricular interaction.

The right and left ventricles cannot be considered independently of one another, and there is evidence of interaction in isolated perfused hearts, ${ }^{1}$ whole animals, ${ }^{234}$ and humans. ${ }^{56}$ Experimental studies and animal models of acute and chronic right ventricular pressure overload have shown that the shape of both ventricles is altered as a result of leftward displacement of the interventricular septum. Also, some echocardiographic studies have shown that patients with right ventricular pressure or volume overload often have impaired left ventricular diastolic function that has been related to the geometrical distortion of the left ventricle. ${ }^{789}$

The aim of this study was to show the abnormalities of left ventricular diastolic function present in a group of patients with right ventricular pressure overload secondary to severe pulmonary hypertension, and to compare these with a control group of patients with right ventricular dilatation but normal pulmonary artery pressures. In this way we hoped to study the possibility of right ventricular disease affecting left ventricular diastolic function, and in particular to separate any direct effects of pulmonary hyper- \\ Cardiac Departme
Royal Brompton \\ Lung Hospital, London \\ S J D Brecker \\ H B Xiao \\ M Mbaissouroum
}


Table 1 Characteristics of the study groups

\begin{tabular}{lll}
\hline & $\begin{array}{l}\text { Pulmonary hypertension } \\
(n=29)\end{array}$ & $\begin{array}{l}\text { Right ventricular dilatation } \\
(n=10)\end{array}$ \\
\hline $\begin{array}{l}\text { Age (y) (mean (SD)) } \\
\text { Aetiology }\end{array}$ & $\begin{array}{l}\mathbf{4 4}(13) \\
\text { Primary pulmonary } \\
\text { hypertension (12) } \\
\text { Pulmonary fibrosis (10) }\end{array}$ & $\begin{array}{l}\mathbf{4 2}(18) \\
\text { Atrial septal defect }(8)\end{array}$ \\
& $\begin{array}{l}\text { Tricuspid valve endocarditis and } \\
\text { repair (1) } \\
\text { Atrial septal defect (5) } \\
\text { Scleroderma (2) }\end{array}$ & \begin{tabular}{l} 
Pulmonary fibrosis (1) \\
\hline
\end{tabular} \\
\hline
\end{tabular}

tension from those of right ventricular dilatation, septal shift, or left ventricular compression.

\section{Patients and methods STUDY POPULATION}

We studied 29 patients (age (mean (range)) 44 (20-63); 17 women) with pulmonary hypertension (12 primary pulmonary hypertension, 10 pulmonary fibrosis, five atrial septal defect (ASD), and two scleroderma), and a control group of 10 patients (age (mean (range)) 42 (1757); 6 women) with right ventricular dilatation (free wall to septal diameter $>2.6 \mathrm{~cm}$ at end systole) but normal pulmonary artery pressure (peak right ventricular to right atrial pressure drop $<35 \mathrm{~mm} \mathrm{Hg}$ ). Table 1 shows the composition of each group. All patients were in sinus rhythm and all had holosystolic tricuspid regurgitation detectable on Doppler. The two patients with scleroderma had no features to suggest involvement of the left ventricle, and there was no hypertrophy of the free wall. No clinical or echocardiographic signs of intrinsic left ventricular disease were found in any other patients. The patients were young and none had symptoms suggestive of coronary artery disease; in the absence of clear clinical indications coronary angiography was not performed.

\section{MODE AND CROSS SECTIONAL} ECHOCARDIOGRAPHY

$M$ mode and cross sectional echocardiograms were taken with the patient in the standard left lateral position, using an Advanced Technical Laboratory Imager $\mathrm{Mk} 300 \mathrm{I}$ with a $3.0 \mathrm{MHz}$ mechanical transducer, or a Toshiba SSH $160 \mathrm{~A}$ imager with a $3.5 \mathrm{MHz}$ transducer. Phonocardiograms were recorded from a Leatham microphone with a low frequency filter. $M$ mode echocardiograms were recorded with simultaneous electrocardiogram and phonocardiogram on a Honeywell (Ecoline 22) strip chart recorder at a paper speed of $10 \mathrm{~cm} / \mathrm{s}$. Aortic valve closure $\left(A_{2}\right)$ was taken as the start of the first high frequency vibration of the aortic component of the second heart sound recorded on the phonocardiogram, and was checked for validity with the aortic echogram and the aortic closure artefact on the Doppler recordings. Left ventricular internal cavity dimensions, septal and posterior wall thickness were measured with leading edge methodology, from the parasternal long axis view at end systole (at $\mathrm{A}_{2}$ ) and end diastole (start of the QRS complex on the electrocardiogram). The right ventricle was measured from end diastolic frames of the apical four chamber view. The short axis was measured transversely at the tip of the tricuspid valve leaflets. Isovolumic relaxation time for the left ventricle was measured from $A_{2}$ to the initial separation of the mitral cusps on the $M$ mode echogram. Interventricular septal motion was analysed from $M$ mode echocardiograms taken at the level of the tips of the mitral leaflets. All measurements were made on three cardiac cycles and the mean was taken.

\section{DOPPLER ECHOCARDIOGRAPHY}

We recorded Doppler signals on a Doptek Spectrascan with a $2.0 \mathrm{MHz}$ transducer, and a Toshiba SSH $160 \mathrm{~A}$ with a $3.5 \mathrm{MHz}$ transducer. Peak transmitral and transtricuspid flow velocities were identified by continuous wave from the apex and were recorded in pulsed mode with a $3 \mathrm{~mm}$ gate and $250 \mathrm{~Hz}$ wall filter. The peak velocities of early " $E$ wave" and atrial "A wave" transmitral flow were recorded and the ratio $\mathrm{E} / \mathrm{A}$ was derived. Tricuspid regurgitant flow was identified and recorded in continuous mode from the apex. The peak instantaneous systolic pressure drop from right ventricle to right atrium was calculated with the modified Bernoulli equation from the peak velocity of the tricuspid regurgitant signal, and the pressure drop at the instant of mitral cusp separation was also recorded. The RR interval was measured from the electrocardiogram, recorded simultaneously with the phonocardiogram. A second measurement of isovolumic relaxation time was obtained for the left ventricle from $\mathrm{A}_{2}$ to the start of mitral flow. The first high frequency vibration of the second component of the second heart sound was taken as $\mathrm{P}_{2}$ and this was checked on the pulmonary echogram and pulmonary closure artefact on Doppler recordings. The time interval from pulmonary closure $\left(\mathbf{P}_{2}\right)$ to the start of tricuspid flow was recorded in all cases. All measurements were made on three cardiac cycles and the mean taken. Intracavity flow was detected within the left ventricle with pulsed Doppler aligned along the ventricular inflow. Having identified flow in pulsed mode, it was recorded in colour Doppler superimposed upon a long axis $M$ mode of the left ventricular cavity from the mitral ring to the apex.

\section{STATISTICAL ANALYSIS}

All values are given as mean (SD). Differences between mean values were compared by Student's $t$ test, and those in incidence by Fisher's exact probability test.

\section{Results}

Tables 2 and 3 show mean values of the measurements. No significant differences were found between the ages or heart rates of pulmonary hypertensive patients and controls.

\section{MODE AND DOPPLER MEASUREMENTS}

Dimensions and septal motion

The internal cavity dimensions of the left ventricle were equally reduced (by the enlarged right ventricle) in both groups of patients, although the septal thickness was greater in 
Table $2 M$ mode measurements of dimensions of the left and right ventricles (mean (SD))

\begin{tabular}{|c|c|c|c|}
\hline Variable & $\begin{array}{l}\text { Pulmonary hypertension } \\
(n=29)\end{array}$ & $\begin{array}{l}\text { Right ventricular } \\
\text { dilatation }(n=10)\end{array}$ & p Value \\
\hline $\begin{array}{l}\text { Left ventricular end diastolic dimension }(\mathrm{cm}) \\
\text { Left ventricular end systolic dimension }(\mathrm{cm}) \\
\text { Septal thickness at } Q \text { wave }(\mathrm{cm}) \\
\text { Posterior wall thickness }(\mathrm{cm}) \\
\text { Right ventricular dimension (short axis) }(\mathrm{cm}) \\
\text { Posterior septal displacement after } \mathrm{A}_{2}(\mathrm{n})\end{array}$ & $\begin{array}{l}3.5(0 \cdot 8) \\
2 \cdot 3(0 \cdot 5) \\
1 \cdot 2(0 \cdot 2) \\
1 \cdot 0(0 \cdot 5) \\
2 \cdot 6(0 \cdot 5) \\
20\end{array}$ & $\begin{array}{l}3.8(0.4) \\
2 \cdot 3(0.4) \\
0.9(0 \cdot 1) \\
0.8(0 \cdot 1) \\
2.9(0.6) \\
0\end{array}$ & $\begin{array}{l}\text { NS } \\
\text { NS } \\
0 \cdot 001 \\
\text { NS } \\
\text { NS } \\
0 \cdot 001\end{array}$ \\
\hline
\end{tabular}

patients with pulmonary hypertension than in controls $(1.24(0.2) v 0.9(0.1) \mathrm{cm}, \mathrm{p}<0.001)$. In 20 of $29(69 \%)$ patients with pulmonary hypertension, early diastolic posterior displacement of the septum was evident on $M$ mode recordings, during isovolumic relaxation of the left ventricle (fig 1). This was not seen, however, in any patients of the control group $(20 / 29 v 0 / 10, \mathrm{p}<0.0001)$. There were no significant differences in the peak systolic right ventricular to right atrial gradient or left ventricular filling pattern between those patients with and without diastolic posterior displacement of the septum.

\section{Dynamics of tricuspid regurgitation and time intervals}

By definition, the peak right ventricular to right atrial pressure gradient was higher in pulmonary hypertensive patients than in controls (60 (16) $v 18(5) \mathrm{mm} \mathrm{Hg}$ ). Tricuspid regurgitation was prolonged in pulmonary hypertensive patients, persisting a mean of $75 \mathrm{~ms}$ after opening of the mitral valve, compared with only $20 \mathrm{~ms}$ in controls. Not only did this reduce the time available for forward tricuspid flow (240 (100) $\mathrm{ms}$ in pulmonary hypertensive patients $v 360(110) \mathrm{ms}$ in controls, $\mathrm{p}=0.012$ ) but, when correlated with events on the left side of the heart, led to a tricuspid pressure drop (ventricular to atrial) of $12(10) \mathrm{mm} \mathrm{Hg}$ still persisting at the time of opening of the mitral valve (compared with $0.4(0.3) \mathrm{mm} \mathrm{Hg}$ in controls, p $<0.001$ ) (figs 1 and 2). This occurred in spite of isovolumic relaxation time of the left ventricle being longer in pulmonary hypertensive patients than controls, whether measured from $A_{2}$ to opening of the mitral valve (80 (25) $v 50(15) \mathrm{ms})$ or from $\mathrm{A}_{2}$ to the start of mitral flow on Doppler (105 (30) $v 60$
(15) ms, p $<0.001)$. Similarly, the time from pulmonary closure to the start of tricuspid flow on Doppler was prolonged in pulmonary hypertensive patients compared with controls (120 (40) v 45 (10) ms, p $<0.001)$. Further significant delay occurred in the start of mitral flow with respect to mitral cusp separation in pulmonary hypertensive patients compared with controls $(30(15) v 10(10) \mathrm{ms}, \mathrm{p}<0.001)$.

\section{Filling patterns}

On the transmitral Doppler $23 / 29(79 \%)$ of the patients with pulmonary hypertension had a dominant "A" wave (23/29 "A fillers"). This pattern of filling was not found in any of the control group, who were all "E fillers"; the difference in incidence was highly significant $(\mathrm{p}<0.0001)$. We found no significant difference in heart rate between the two groups of patients. Within the group with pulmonary hypertension, "A fillers" had a longer isovolumic relaxation time than the "E fillers" $(100(25) v 60(20) \mathrm{ms}, \mathrm{p}<0.001)$.

\section{Intracavity flow}

In six patients with pulmonary hypertension, intracavity flow was noted during isovolumic relaxation. All six patients showed posterior displacement of the interventricular septum after aortic closure. Compared with the group as a whole, no significant differences occurred in duration of isovolumic relaxation, ventricular filling times, or filling pattern in patients with intracavity flow.

\section{Discussion}

In common with previous studies, we have found impaired left ventricular diastolic function in our patients with pulmonary hyperten-

Table 3 Doppler and $M$ mode characteristics (mean (SD))

\begin{tabular}{|c|c|c|c|}
\hline Variable & $\begin{array}{l}\text { Pulmonary hypertension } \\
(n=29)\end{array}$ & $\begin{array}{l}\text { Right ventricular } \\
\text { dilatation }(n=10)\end{array}$ & p Value \\
\hline RR Interval (ms) & $660(250)$ & $750(130)$ & NS \\
\hline RV-RA pressure drop (mm Hg) & $60(16)$ & $18(5)$ & $<0.001$ \\
\hline $\begin{array}{l}\text { Left ventricular isovolumic relaxation time (ms): } \\
\text { A2-MVO } \\
\text { A2-MV flow }\end{array}$ & $\begin{array}{r}80(25) \\
105(30)\end{array}$ & $\begin{array}{l}50(15) \\
60(15)\end{array}$ & $\begin{array}{l}<0.001 \\
<0.001\end{array}$ \\
\hline $\begin{array}{l}\text { P2-TV flow (ms) } \\
\text { A2-end of TR (ms) } \\
\text { P2-end of TR }(\mathrm{ms})\end{array}$ & $\begin{array}{l}120(40) \\
155(60) \\
115(60)\end{array}$ & $\begin{array}{l}45(10) \\
70(15) \\
40(15)\end{array}$ & $\begin{array}{l}<0.001 \\
<0.001 \\
<0.001\end{array}$ \\
\hline RV-RA pressure drop at $\mathrm{MVO}(\mathrm{mm} \mathrm{Hg})$ & $12(10)$ & $0.4(0.3)$ & $<0.001$ \\
\hline $\begin{array}{l}\text { Mitral filling velocity: } \\
\text { E }(\mathrm{m} / \mathrm{s}) \\
\text { A }(\mathrm{m} / \mathrm{s}) \\
\text { E } / \text { A ratio }\end{array}$ & $\begin{array}{l}0.3(0 \cdot 2) \\
0.55(0 \cdot 2) \\
0.5(0 \cdot 4)\end{array}$ & $\begin{array}{l}0.6(0.3) \\
0.4(0 \cdot 1) \\
1.8(0.9)\end{array}$ & $\begin{array}{l}<0.002 \\
<0.002 \\
<0.001\end{array}$ \\
\hline Delay in onset of mitral flow (MVO-MV flow) (ms) & $30(15)$ & $10(10)$ & $<0.001$ \\
\hline
\end{tabular}

RV, right ventricle; RA, right atrium; MVO, mitral valve opening; MV, mitral valve; TV, tricuspid valve; TR, tricuspid regurgitation. 
Figure 1 M mode echocardiogram of the left ventricular cavity

(above), and continuous wave Doppler display of tricuspid regurgitation (below), from a patient with pulmonary

hypertension. Note the posterior displacement of the interventricular septum (arrowed). This septal "dip" occurs during isovolumic relaxation of the left ventricle. Note that at the instant of mitral valve opening, tricuspid regurgitation continues, with a velocity of $2.25 \mathrm{~m} / \mathrm{s}$, corresponding to a right ventricular to right atrial pressure difference of $20 \mathrm{~mm} \mathrm{Hg}$ Electrocardiogram (ECG) and phonocardiogram (PCG) are shown.

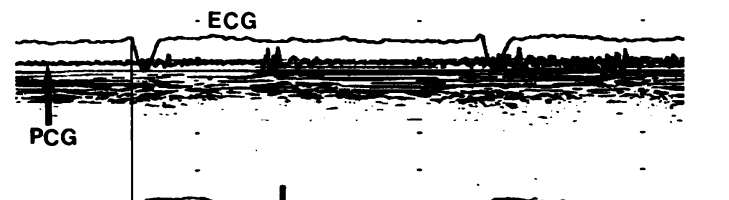

earliest start of detectable transmitral flow by pulsed Doppler. Also, ventricular dimension characteristically fell during isovolumic relaxation, indicating a change in cavity shape, and in six patients, intracavity flow was detected.

Several mechanisms have been proposed to explain how right sided abnormalities can disturb left ventricular diastolic function in the absence of left ventricular diastolic disease. Distension or hypertrophy of the right ventricle may compress the left, thus altering chamber stiffness. Raised diastolic pressures from the right may directly affect those of the left, possibly by moving the septum, or the interaction may be indirect and involve the pericardium. In our study we aimed to investigate these possibilities in more detail.

The characteristic disturbances of isovolumic relaxation that we saw in our patients suggest that whatever the mode of interaction between the two ventricles it was already operating before mitral valve opening. This makes it unlikely that the primary disturbance was simply one of passive ventricular pressure and volume relations. Neither did pericardial restraint appear to be important as this is also a late diastolic phenomenon and it is difficult to see how such restraint could possibly affect isovolumic relaxation. Our patients all showed the characteristic anatomical findings of right ventricular dilatation with corresponding compression of the left ventricle, often with reversed septal motion. To investigate this possible mechanism we used a control group of patients with identical anatomical abnormalities, but in whom right ventricular systolic pressures were normal. Left ventricular diastolic function was effectively normal in this group. We concluded, therefore, that disturbed left ventricular diastolic function in our patients with pulmonary hypertension could not be attributed to reduced right ventricular diastolic compliance, pericardial interaction, left ventricular compression, or any other direct result of right ventricular dilatation, but seemed to be much more closely related to the presence of the pulmonary hypertension itself.

Not only is peak pressure in the pulmonary artery raised in patients with pulmonary hypertension, but the rate of fall is reduced, ${ }^{11}$ so the pressure pulse lasts longer. This may show itself in several ways. The interval from pulmonary valve closure to tricuspid opening is increased $^{1213}$ and the duration of the Doppler signal of functional tricuspid regurgitation is strikingly prolonged so that it may persist $100 \mathrm{~ms}$ or more after $\mathrm{P}_{2}$. These findings are so consistent that they can be used to estimate peak pressure in the right ventricle in individual patients. ${ }^{13-15}$ Effectively, therefore, pulmonary hypertension causes decline of right ventricular tension to be prolonged; with tricuspid regurgitation as a marker, this prolongation beyond pulmonary closure is considerable, being on average $3 \mathrm{~ms}$ for every $1 \mathrm{~mm} \mathrm{Hg}$ rise in pressure in the right ventricle. ${ }^{15}$ In our present study we were particularly concerned to examine the effects on left sided events. We found that tricuspid regurgitation consistently continued beyond open- 
ing of the mitral valve, and that at the time of mitral cusp separation a mean gradient of $12 \mathrm{~mm} \mathrm{Hg}$ from right ventricle to right atrium still existed. Thus tension in the right ventricle continues to decline throughout, and beyond isovolumic relaxation of the left ventricle. It is likely that tension within the interventricular septum is equally prolonged. This would explain the displacement of the posterior septum and associated fall in the dimension of the left ventricle seen in the patients with pulmonary hypertension but not in the controls. This septal shift will have contributed to the incoordinate wall motion seen during isovolumic relaxation, and thus to delaying the opening of the mitral valve and the start of filling as well as to the abnormal intracavity flow.

The period of isovolumic relaxation is critical to normal filling. Prolonged or disorganised isovolumic relaxation has important consequences on function later in diastole, reducing early velocity diastolic filling and causing a corresponding increase in velocity during atrial systole. This effect has been shown in hypertrophic cardiomyopathy, ${ }^{16}$ coronary artery disease, ${ }^{17}$ and left ventricular hypertrophy due to aortic stenosis. ${ }^{18} \mathrm{We}$ suggest that our findings represent yet another example of the interaction between isovolumic relaxation and ventricular filling, and as the disturbances in filling of the left ventricle were so typical of those previously described, we think that no other explanation for them need be sought. Even within our group of patients with pulmonary hypertension, "A fillers" had a significantly longer isovolumic relaxation time than "E fillers". The effects of a diastolic pressure gradient across the septum on ventricular septal motion have been recognised for some time, both in whole animals, ${ }^{2}$ and humans with pulmonary hypertension, ${ }^{6}$ but such gradients have been associated with raised right ventricular diastolic pressure due to disturbed compliance and thus occur during ventricular filling; hence they are different in their mechanism and timing to those we have described. Similarly, left ventricular asynchrony has been recognised in pulmonary hypertension, ${ }^{10}$ but again this was only apparent during filling and events during isovolumic periods were specifically excluded from this study. That a pressure gradient across the septum may disorganise isovolumic relaxation and thus disturb filling does not appear to have been previously proposed.

This study highlights a potential problem of nomenclature that will become increasingly important once it is recognised that systole and diastole need not be synchronous on the two sides of the heart. In our patients decline of right ventricular tension during late systole corresponded to early left ventricular diastole and this asynchrony had important practical consequences. It, in fact, represents a novel mode of ventricular interaction that has received little attention, and it also provides further evidence of the importance of isovolumic relaxation of the left ventricle in determining events for the remainder of diastole.

S J D B is supported by a British Heart Foundation junior research fellowship and $\mathrm{H} \mathrm{B} \mathrm{X} \mathrm{by} \mathrm{the} \mathrm{Brompton} \mathrm{Hospital}$ Special Cardiac Fund.

1 Weber KT, Janicki JS, Shroff S, Fishman AP. Contractile mechanics and interaction of the right and left ventricles. Am J Cardiol 1981;47:686-95.

2 Kingma IK, Tyberg JV, Smith ER. Effects of diastolic transseptal pressure gradient on ventricular septal transseptal pressure gradient on ventricular
position and motion. Circulation 1983;68:1304-14.

3 Visner MS, Arentzen CE, Crumbley III AJ, Larson EV O'Connor MJ, Anderson RW. The effects of pressureinduced right ventricular hypertrophy on left ventricular diastolic properties and dynamic geometry in the conscious dog. Circulation 1986;74:410-9.

4 Goldstein JA, Harada A, Yagi Y, Barzilai B, Cox JL. Hemodynamic importance of systolic ventricular interaction, augmented right atrial contractility and atrioventricular synchrony in acute right ventricula dysfunction. J Am Coll Cardiol 1990;16:181-9.

5 Jessup M, St John Sutton M, Weber KT, Janicki JS. The effect of chronic pulmonary hypertension on left ventricular size, function and interventricular septal motion.
trion tricular size, function and inter.

6 Tanaka H, Tei C, Nakao S, Tahara M, Sakurai S, Kashima T, Kanehisa T. Diastolic bulging of the interventricular septum toward the left ventricle: An echocardiographic septum toward the left ventricle: An echocardiographic
manifestation of negative interventricular pressure manifestation of negative interventricular pressure gradient between left and right
Circulation 1980;62:558-63.

7 Ryan T, Petrovic O, Dillon JC, Feigenbaum H, Conley MJ, Armstrong WF. An echocardiographic index for separation of right ventricular volume and pressure overload. $J$ Am Coll Cardiol 1985;5:918-24.

8 Louie EK, Rich S, Brundage BH. Doppler echocardiographic assessment of impaired left ventricular filling in patients with right ventricular pressure overload due to primary pulmonary hypertension. J Am Coll Cardiol 1986;6:1298-306.

9 Dittrich HC, Chow LC, Nicod PH. Early improvement in left ventricular diastolic function after relief of chronic right ventricular pressure overload. Circulation 1989; right ventricu

10 Bhargava V, Sunnerhagen KS. Left ventricular asynchrony in patients with pulmonary hypertension. J Appl Physiol

11 Triffon D, Groves BM, Reeves JT, Ditchey RV. Determinants of the relation between systolic pressure and duration of isovolumic relaxation in the right ventricle. $\mathrm{J} \mathrm{Am} \mathrm{Col}$ Cardiol 1988;11:322-9.

12 Burstin L. Determination of pressure in the pulmonary artery by external graphic recordings. Br Heart 1967;29:396-404.

13 Hatle L, Anglesen BAJ, Tromsdal A. Non-invasive estimation of pulmonary artery systolic pressure with Doppler ultrasound. Br Heart $J$ 1981;45:157-65.

14 Stevenson JG, Kawabori I, Guntheroth WG. Noninvasive estimation of peak pulmonary artery pressure by $\mathbf{M}$-mode echocardiography. J Am Coll Cardiol 1984;4:1021-7.

15 Brecker SJD, Xiao HB, Stojnic BB, Mbaissouroum M, Gibson DG. Assessment of the peak tricuspid regurgitant velocity from the dynamics of retrograde flow. Int J velocity from the dynamic
Cardiol 1992;34:267-71.

16 Sanderson JE, Gibson DG, Brown DJ, Goodwin JF. Left ventricular filling in hypertrophic cardiomyopathy. An ventricular filling in hypertrophic cardiomyopa
angiographic study $B r$ Heart $J$ 1977; 39:661-70.

17 Fioretti P, Brower RW, Meester GT, Serruys PW. Interaction of left ventricular relaxation and filling during early diastole in human subjects. Am J Cardiol 1980;46: 197-203.

18 Lee CH, Hogan JC, Gibson DG. Diastolic disease in left ventricular hypertrophy: comparison of $M$ mode and Doppler echocardiography for the assessment of rapid ventricular filling. Br Heart J 1991;65:194-200. 